\title{
ТЕХНОЛОГИЯ
}

\section{КРИТИЧЕСКОГО МЫШЛЕНИЯ - ОДИН ИЗ СПОСОБОВ РЕАЛИЗАЦИИ СТРАТЕГИЙ СМЫСЛОВОГО ЧТЕНИЯ}

Дамдинова Т. Б.

Балсанова Э. Б. Цырендоржиева Е. В. МАОУ «Гимназия № 33 г.Улан-Удэ»

\begin{abstract}
Аннотация: Наиболее актуальными в современной системе образования становятся так называемые softskills (гибкие непредметные навыки): критическое мышление, креативность, координация, коммуникация и кооперация. Решением проблемы развития softskills занимается современная школа, ориентируясь на ФГОС, в котором это направление отражается.
\end{abstract}

Ключевые слова: критическое мышление, смысловое чтение, softskills.

\section{CRITICAL THINKING TECHNOLOGY IS ONE OF THE WAYS TO IMPLEMENT SEMANTIC READING STRATEGIES}

Damdinova T. B. Balsanova E. B. Tsyrendorzhieva E. V.

Главное в чтении - не текст сам по себе, а мысли, чувства, образы, вопросы, которые рождаются в душе читателя Н. А. Рубакин

Технология критического мышления - ведущая технология для современной системы образования. Смысловое чтение - важнейший метапредметный навык и составляющая реализации ФГОС. Поэтому актуальность данного направления несомненна важна. Смысловое чтение - вид чтения, которое нацелено на понимание читающим смыслового содержания 
текста. Развитие способностей смыслового чтения помогут овладеть искусством аналитического и критического чтения. Владение навыками смыслового чтения позволяет продуктивно учиться по книгам всегда.

Цель смыслового чтения - максимально точно и полно понять содержание текста, уловить все детали и практически осмыслить извлеченную информацию. Это внимательное вчитывание и проникновение в смысл с помощью анализа текста. Когда человек действительно вдумчиво читает, то у него обязательно работает воображение, он может активно взаимодействовать со своими внутренними образами. Человек сам устанавливает соотношение между собой, тестом и окружающим миром. Когда ребенок владеет смысловым чтение, то у него развивается устная речь и, как следующая важная ступень развития, речь письменная [5, с. 3].

Смысловое чтение не может существовать без познавательной деятельности. Ведь для того, чтобы чтение было смысловым, учащимся необходимо понимать содержание текста, составлять свою систему образов, осмысливать информацию, осуществлять познавательную деятельность. Существует множество способов организации познавательной деятельности, способствующих развитию навыка смыслового чтения такие как: проблемнопоисковый способ, дискуссия, обсуждение, моделирование, рисунок. Смысловое чтение отличается от любого другого чтения тем, что при смысловом виде чтения происходят процессы постижения читателем ценностно-смыслового момента, осуществляется процесс интерпретации, наделения смыслом. Одним из путей развития читательской грамотности является стратегиальный подход к обучению смысловому чтению. В концепции универсальных учебных действий (Асмолов А. Г., Бурменская Г. В., Володарская И. А. и др.) выделены действия смыслового чтения, связанные с:

- осмыслением цели и выбором вида чтения в зависимости от коммуникативной задачи;

- определением основной и второстепенной информации:

-формулированием проблемы и главной идеи текста.

Для осмысления понимания недостаточно просто прочесть текст, необходимо дать оценку информации откликнуться на содержание.

Поскольку чтение является метапредметным навыком, то составляющие его части будут в структуре всех универсальных учебных действий:

-в личностные УУД входят мотивация чтения, мотивы учения, отношение к себе и к школе; -в регулятивные УУД - принятие учеником учебной задачи, произвольная регуляция деятельности; 
-в познавательные УУД - логические и абстрактное мышление, оперативная память, творческое воображение, концентрация внимания, объем словаря.

Работа с любым текстом предполагает: 3 основных стратегии

- стратегии предтекстовой деятельности

Целью этой деятельности является

- постановка цели и задач чтения,

- актуализация или знакомство с важными понятиями, терминами,

○ актуализация предшествующих знаний,

○ прогнозирование содержания,

○ формирование умения и привычки думать над книгой до чтения.

- стратегии текстовой деятельности

Целью этой деятельности на исполнительной фазе чтения является

- $\quad$ развитие его механизмов, то есть выдвижение гипотез и смысловая догадка

- размышление во время чтения о том, что и как мы читаем и насколько хорошо понимаем прочитанное.

Основным принципом этого этапа является

- остановка деятельности, размышление вслух,

- $\quad$ прогноз и установление разнообразных связей в развития сюжета.

Учитель вмешивается в процесс чтения обучающегося с целью помочь или предоставить дополнительную информацию и просто обучить.

- стратегии послетекстовой деятельности.

Целью этой деятельности является

- применение, использование материала в разных ситуациях, усвоение, расширение, прочитанного,

- $\quad$ происходит корректировка читательской интерпретации авторским смыслом.

Работая с ребятами младшего школьного возраста над разными текстами, мы заметили,

\section{Проблемы:}

- $\quad$ дети имеют низкую скорость чтения, вследствие чего тратят много времени на подготовку домашних заданий,

- $\quad$ зачастую они не понимают смысла, прочитанного из-за ошибок при чтении

текста, выделить главное в прочитанном, 
- затрудняются кратко пересказать содержание,

- при выполнении самостоятельной работы обучающиеся допускают ошибки по причине непонимания формулировки задания,

В своей работе мы старались найти такие методы и приёмы работы с художественным и научным текстом, которые бы совершенствовали мыслительные способности учащихся и позволили бы мыслить более продуктивно. Известно, что любое знание будет лучше и качественнее, если оно будет основано на собственном опыте. Вызвать на поверхность представления или более устойчивые формы знания ученика по изученной теме - задача нелегкая, но она многократно упростит ребятам путь к новым знаниям и умениям.

Изучив методическую литературу и передовой опыт использования современных технологий обучений, мы пришли к выводу, что для решения проблем обучения навыкам смыслового чтения на уроках в начальной школе целесообразно использовать технологию развития критического мышления через чтение и письмо (или сокращенно - РКМЧП)

Технология развития критического мышления - универсальная, проникающая, "надпредметная” технология, открытая к диалогу с другими педагогическими подходами и технологиями.

В её основе - ведущие теории современного образования и теории, разработанные выдающимися советскими и российскими педагогами и психологами 20 века. В этом смысле её можно назвать интеграционной технологией, которая обеспечивает целостный, системный подход к обучению.

Дать определение термина критическое мышление непросто: слишком много различных параметров - умений, видов деятельности, ценностей - он в себя включает. Так, о чем мы, собственно, говорим, когда произносим: критическое мышление?

Но авторы данной технологии предлагают своё определение критического мышления: «Думать критически означает проявлять любознательность и использовать исследовательские методы: ставить перед собой вопросы и осуществлять планомерный поиск ответов». Критическое мышление работает на многих уровнях, не довольствуясь фактами, а вскрывая причины и следствия этих фактов.

Критическое мышление - это самостоятельное мышление. Оно начинается от постановки вопросов, строится на основе убедительной аргументации. Каждый ученик сам формулирует свои идеи, оценки и убеждения независимо от остальных. Ученики должны иметь достаточно 
свободы, чтобы думать собственной головой и самостоятельно решать даже самые сложные вопросы.

Ценность данной технологии (РКМЧП) в том, что она учит детей слушать и слышать, развивает речь, даёт возможность общения, активизирует мыслительную деятельность, познавательный интерес, побуждает детей к действию, поэтому работают все. - это очень важный момент для младших школьников.

Педагогическая идея: Использование приемов технологии развития критического мышления при работе с текстом на уроках в начальной школе позволит создать условия для реализации стратегий смыслового чтения.

Технология критического мышления через чтение и письмо (РКМЧП)

Цель: осуществление сотрудничества педагога с учащимися в ходе учебной деятельности по развитию критического мышления и реализации стратегий смыслового чтения на уроках

\section{Задачи:}

- с сформировать у учащихся умения концентрироваться на учебной проблеме, собирать и осмысливать текстовую информацию;

- адаптировать педагогические приемы применения технологии РКМЧП к процессу преподавания в начальной школе;

- создать условия для активной познавательной деятельности учащихся.

К стратегиям смыслового чтения относится технологии, направленные на развитие критического мышления учеников. Критическое мышление означает процесс соотнесения внешней информации с имеющимися у человека знаниями, выработка решений о том, что можно принять, что необходимо дополнить, а что - отвергнуть. При этом возникают ситуации, когда приходится корректировать собственные убеждения или даже отказываются от них, если они противоречат новым знаниям. [3]

Методологические основы критического мышления включают три стадии, которые должны присутствовать на уроке познания.

\section{Что нравится в самой технологии?}

Базовая модель технологии вписывается в урок и состоит из трёх этапов. Для того чтобы дать детям возможность активно работать с получаемым знанием, авторы технологии предполагают строить урок по привычной схеме:

«введение - основная часть - заключение».

Подобная же схема действует и при решении проблем: 
«введение в проблему - подходы к ее решению - рефлексия результата».

В рамках технологии РКМЧП данные этапы получили несколько иные названия.

Каждая стадия свои цели и задачи, а также набор приемов, направленных сначала на активизацию деятельности, а потом на осмысление и обобщение приобретенных знаний.

Рассмотрим первую стадию

- Первая стадия - «вызов», во время которой у учащихся активизируются имевшиеся ранее знания, определяются цели изучения предстоящего учебного материала.

- Вторая стадия - «осмысление» в ходе, которой и происходит непосредственная работа ученика с текстом. Процесс чтения всегда сопровождается действиями ученика (пометки, составление таблиц), которые позволяют отслеживать собственное понимание. При этом понятие «текст» трактуется весьма широко: это и письменный текст, и речь преподавателя, и видеоматериал.

- Третья стадия - «рефлексия» на этом этапе ученик формирует личное отношение к тексту, фиксирует его, либо высказывает свою позицию в ходе обсуждения

Рассмотрим подробнее каждый из приведенных этапов и те методы, и приемы, которые на них можно использовать:

\section{1) Стадия - «вызов»,}

На данном этапе вызова ученик «вспоминает», что ему известно по изучаемому вопросу, делает предположения, задает вопросы, на которые хочет получить ответы.

Методом демонстрации процесса мышления является модели, рисунки, схемы и т.п. отражают взаимоотношения между идеями, показывают учащимся ход мыслей. Процесс мышления, становится наглядным.

Стройная система приемов включает в себя, как способы организации индивидуальной работы, так и ее сочетания с парной и групповой работой.

В процессе реализации стадии вызова важно:

- Давать учащимся возможность высказывать свою точку зрения по теме свободно.

- Фиксировать все высказывания. При этом на данном этапе нет «правильных» и «неправильных» высказываний.

Роль учителя - корректирующая. 
Разнообразие методов говорит о возможности мобилизующего начала Перечислим некоторые Приёмы стадии «Вызова»:

№1. Показ иллюстрации +

№2. Зачитывание отрывка из художественной книги

№3. Показ отрывка из фильма +

№4. Работа с текстом

№5. Ряды понятий. +

№ 6. «Верите или вы?..»

№ 7 Кластер

2) Стадия осмысления

Вторая стадия осмысления направлена на:

- получение новой информации и корректировку учеником поставленных целей

Ученик читает (слушает) текст, используя активные методы чтения, делает пометки на полях или ведет записи по мере осмысления новой информации.

На фазе осмысления учащиеся:

- осуществляют контакт с новой информацией;

- сопоставляют эту информацию с уже имеющимися знаниями и опытом;

- $\quad$ обращают свое внимание на поиск ответов на возникшие вопросы

- $\quad$ готовятся к анализу и обсуждению услышанного или прочитанного.

Учитель на данном этапе:

- Может быть непосредственным источником новой информации

- Предлагает различные приемы для вдумчивого чтения и размышления о прочитанном.

\section{Приёмы стадии «Осмысление»:}

№1. Составление "тонких" и "толстых" вопросов

№2. Текст с пропусками важных слов

№3. Интерпретация карты, таблицы, схемы

№4. Составление суждений "верно ли, что..."

№5. Составление задания "Три подсказки"

№6. Составление плана текста

№7. Сопоставление текстов 


\section{Стадия рефлексии}

Эта стадия необходима не только для того, чтобы учитель проверил память своих учеников, но и того, чтобы они сами смогли проанализировать, удалось ли им достичь поставленных целей и решить проблемы, возникшие в процессе знакомства с новым материалом.

\section{Здесь ученики}

- систематизируют новую информацию по отношению к своим представлениям.

- выражают новую информацию собственными словами,

- самостоятельно выстраивают связи.

Этап рефлексии активно способствует развитию навыков критического мышления.

\section{Учителю следует:}

- вернуть учащихся к первоначальным записям-предположениям;

- $\quad$ внести изменения;

- $\quad$ дать творческие, исследовательские или практические задания на основе изученной информации

\section{Формы предъявления рефлексии разные}

Устная форма: диалог между одним учеником и учителем, диалог между двумя учениками, игровые методы, круглый стол.

Письменная форма: выбор из предложенных вариантов, Логические цепочки, согласие несогласие с утверждениями.

Графические, схематические способы представления информации в виде таблиц, графиков, диаграмм, кластеров.

Творческие задания: синквейн, письмо, мини-сочинение.

Приемы

№1. Ответы на поставленные в начале урока вопросы

№2. Организация устных и письменных круглых столов

№3. Написание творческих работ - эссе

№4. Составление "синквейна" или "диаманта"

№5. Создание «кластеров» или сводных таблиц, работа с таблицами

№6 «Три подсказки»

№ 7 «Концептуальная таблица»

Технология развития критического мышления предлагает разнообразный набор приёмов и методов для осуществления всех этапа работы с текстами разных видов, а также включает способы организации индивидуальной работы, и её сочетания с парной и групповой работой. 
Данная технология используется нами не только на уроках, но и во всем учебно-воспитательном процессе. Применение технологии развития критического мышления через чтение и письмо (ТРКМЧП) положительно влияет на формирование читательской компетентности младшего школьника, осознание себя как грамотного читателя, на формирование способности к использованию читательской деятельности как средства самообразования.

Применение технологии РКМ позволяет не присваивать «готовое» знание, а конструирует свое, которое рождается в процессе обучения. Тексту в данном случае отводится приоритетное значение: его читают, анализируют, трансформируют, интерпретируют, ведут дискуссии.

\section{Развитие критического мышления приводит к следующим результатам:}

- Высокая мотивация учащихся к образовательному процессу.

- Возрастание мыслительных возможностей учащихся, гибкости мышления, его переключения с одного типа на другой.

- Развитие способности самостоятельно конструировать, строить понятия и оперировать ими.

- Развитие способности передавать другим авторскую информацию, подвергать ее коррекции, понимать и принимать точку зрения другого человека.

- Развитие умения анализировать полученную информацию.

- Решать учебно-познавательные и учебно-практические задачи, требующие полного и критического понимания текста).

\section{Список литературы}

1. Бондаренко Г. И. Развитие умений смыслового чтения в начальной школе / Г. И. Бондаренко // Начальная школа плюс: до и после // Электронный pecypc www.school 2100.ru.

2. Долженко Ю. А. Методическое сопровождение личностноориентированного образования [Текст]. Б., 2003. - 134 с.

3. Заир-бек С. И. Развитие критического мышления на уроке: пособие для учителей общеобразовательных учреждений / С. И. Заир-бек, И. В. Муштавинская. М.: Просвещение, 2009 
4. Мельникова Е. Л. Проблемный урок, или как открывать знания с учениками. Пособие для учителей [Текст]. - М.: Просвещение, 2002. - 345 с.

5. Сапа А. В. Формирование основ смыслового чтения в рамках реализации ФГОС основного общего образования. Педагогическая мастерская. Все для учителя.№ 10 октябрь 2014.

6. Селевко Г. К. Современные образовательные технологии [Текст]. М.: Издательство «Первое сентября», 1998. - 321 с. 15.

7. Федеральный государственный стандарт основного общего образования: утвержден приказом Министерства образования и науки Российской Федерации от «17» декабря 2010 г. № 1897

8. Якиманская И. С. Личностно-ориентированное обучение в современной школе [Текст]. - М., 1996. - 142 с.

(C) Т. Б. Дамдинова, Э. Б. Балсанова, Е. В. Цырендоржиева, 2021 